\title{
PENGELOLAAN AGROFORESTRY TRADISIONAL "DUSUNG” BERBASIS KEARIFAN LOKAL “MASOHI” OLEH MASYARAKAT DESA HULALIU-KABUPATEN MALUKU TENGAH
}

\author{
MANAGEMENT TRADITIONAL AGROFORESTRY" DusUng " BASED ON LOCAL \\ WISDOM" Masohi " HULALIU VILLAGE IN DISTRICT CENTRAL MOLUCCAS
}

\begin{tabular}{|c|c|}
\hline $\begin{array}{l}\text { Mersi } \\
\text { (Staf P }\end{array}$ & $\begin{array}{l}\text { dan Moda Talaohu,S.Hut.MSc } \\
\text { Fakultas Pertanian Universitas Pattimura) } \\
\text { pus Poka Ambon } 97237 \\
\text { ail: mersisahu@gmail.com }\end{array}$ \\
\hline \multicolumn{2}{|c|}{\begin{tabular}{l|l} 
Penulis Korespondensi Email: mersisahu@ gmail.com \\
Disetujui: 3 Agustus 2018
\end{tabular}} \\
\hline
\end{tabular}

\begin{abstract}
Abstrak
Pengelolaan agroforestry tradisional dusung sebagai salah satu model pemanfaatan lahan dan hutan di Maluku khususnya oleh masyarakat desa Hulaliu memberikan manfaat baik ekonomi, ekologi dan social budaya yang masih tetap dipertahankan hingga kini. Dan salah satu tradisi dan budaya yang masih tetap dilakukan oleh masyarakat dalam pengelolaan agroforestry yakni gotong-royong "masohi yang dilakukan mulai dari: persiapan lahan, penanaman, pemeliharaan, pemanenan, pemasaran dan pengelohan pasca panen yang dirasakan sangat membantu meringankan dan memudahkan pekerjaan. Jenis-jenis kerja masohi diantaranya : 1) Masohi bilang 2) Masohi balas 3) Masohi kumpul. Sedangkan dari segi manajemen pengelolaan dusung di desa Hulaliu memiliki karakter dan ciri tersendiri didasarkan pada manajemen pengelolaan hutan yakni terdiri dari : perencanaan (planning), pengorganisasian (organization), pelaksanaan (actualization) dan pengawasan (controlling). Pengembangan yang dilakukan dalam pengelolaan agroforestry tradisional dusung sebagai upaya peningkatan kapasitas petani dan potensi dusung antara lain ; sosialisasi dan penyuluhan tentang pengelolaan agroforestry,l pengadaan peralatan produksi dan pemasaran hasil dusung, pengkayaan jenis tanaman di dusung dan pendampingan kelompok tani.
\end{abstract}

Kata Kunci : Pengelolaan, Dusung, Masohi.

\begin{abstract}
Management of traditional agroforestry 'dusung' as one model of land use and forest in Mollucas, specially by community Hulaliu village benefit both economic , ecological and social culture that is still maintained until now . And one of the traditions and culture that is still done by the community in the management of agroforestry is the gotong-royong " Masohi performed star by : land preparation, planting, maintenance , harvesting , marketing and post-harvest management felt very help and easy the work. Masohi types work are: 1 ) said of Masohi 2 ) response of Masohi 3 ) Collect of Masohi. In terms of the management of Dusung in Hulaliu village has its own character and traits based on the forest management consists of : plannining, organization, actualization and controlling. Development carried out in the management of tradisional agroforestry dusung as an effort to increase the farmers capacity and dusungs potential,such as : socialization and counseling about the agroforestry management,procurement of production equipment and marketing results, enrichment of plants in dusung and group assistance.
\end{abstract}


Keywords : Management, Dusung, Masohi . PENDAHULUAN

Pengelolaan dusung sebagai salah satu bentuk agroforestry tradisional di Maluku telah banyak memberikan manfaat baik ekonomi, ekologi dan social budaya dan oleh masyarakat system pengelolaan dusung masih tetap dipertahankan keberlanjutanannya hingga kini sebagai kearifan local masyarakat Maluku dalam

kearifan local merupakan pengetahuan kebudayaan yang dimiliki oleh suatu masyarakat tertentu yang mencakup sejumlah pengetahuan kebudayaan yang berkenan dengan modelmodel pengelolalaan sumberdaya alam secara lestari. Dan salah satu bentuk kearifan local yang masih dipertahankan Masyarakat desa Hulaliu juga memiliki ikatan kekeluargaan dan adat yang sangat kental dalam kehidupan keseharian masih tetap diterapkan. "Masohi" yang dalam bahasa daerah setempat artinya "gotong-royong" merupakan salah satu bentuk penerapan kearifan local yang masih dipertahankan hingga saat ini yakni tradisi saling-

Pengelolaan dusung berbasis kearifan local "masohi" yang oleh masyarakat desa Hulaliu masih tetap dipertahankan dalam sistem pertanian kehutanan yang memiliki aspek nilai sosial budaya, ekonomi dan pengelolaan sumber daya alam khususnya di darat. Dengan berbagai kearifan local yang dimiliki oleh masyarakat baik menyangkut kepercayaan dan atau pantangan, etika dan aturan, teknik dan teknologi, praktek dan tradisi pengolahan hutan/lahan maka masyarakat dengan sendirinya dapat berproses dalam mengelolah dan mengusahakan dusung yang dimilikinya.

oleh masyarakat dalam pengelolaan agroforestry tradisional dusung yakni “masohi”Masohi merupakan salah satu bentuk sikap gotong-royong dalam mengerjakan suatu pekerjaan yang dalam pengelolaan dusung dilakukan dilakukan secara berkelompok.

membantu/gotong-royong dalam mengerjakan suatu pekerjaan misalnya pengelolan dusung lahan maupun membangun rumah dan pekerjaan lain. Masohi dalam pengelolaan dusung dirasakan sangat besar manfaatnya dalam meringankan pekerjaan petani dari saat membuka ladang hingga pemanenan hasil tergantung kesepakatan kelompok masohi. ekologi mampu mempertahankan interaksi masyarakat dengan hutan maupun interaksi antar komunitas dalam masyarakat pengelolah hutan yang bersifat adaptif. Dengan demikian penerapan prinsip dan 
konsep manajemen dalam pengelolaan sederhana dapat mempertahankan keberlanjutan dan kelestarian hasil hutan demi kesejahteraan masyarakat.

Dengan demikian perlunya mempertajam pengetahuan masyakarakat tentang kearifan lokal dan adanya upaya untuk meningkatan peran petani dalam pengelolaan dusung.Namun apakah hal tersebut dinilai signifikan dalam meningkatkan peran serta masyarakat dalam pembangunan kehutanan dan meningkatkan kesejahteraan masyarakat? Untuk itu diperlukan suatu konsep strategi pengelolaan yakni suatu kerangka pengelolaan hutan berbasis kearifan local

\section{METODE PENELITIAN}

Penelitian dilaksanakan di desa Hulaliu kecamatan Pulau Haruku pada bulan April - Mei 2018. Dalam penelitian menggunakan metode survei dan observasi yakni mengambil sampel dari satu populasi dan menggunakan kuisioner sebagai alat pengumpulan data yang pokok. Pengambilan sampel dilakukan secara purposive dengan jumlah

Pengolahan dan analisis data dalam penelitian ini adalah deskripsi kualitatif dengan tujuan untuk menggambarkan fenomena tertentu secara lebih kongrit dan terperinci. Dalam penelitian ini metode hutan oleh masyarakat walaupun sangat

yang dapat menjawab paradigm pengelolalan hutan. Adapun tujuan dalam penelitian ini adalah Mengetahui pola pengelolaan dusung yang dilakukan oleh masyarakat desa Soya; Mengkaji penerapan konsep manajemen dalam pengelolaan dan pengembangan dusung oleh masyarakat desa Hulaliu; dan Mengetahui pola masohi dalam pengelolaan agroforestry tradisional dusung.

respondens sebanyak 18 respondes yang berasal dari 2 kelompok tani yakni kelompok tani Ima ama dan kelompok tani Pamahanu. Sedangkan data yang kumpulkan antara lain data primer yang diperoleh langsung dari respondens melalui interview meliputi : identitas respondens dan interaksi dengan dusung. Untuk data sekunder diperoleh dari pemerintah desa maupun dari instansi terkait.

deskripsi kualitatif yang digunkan memberikan penekanan pada aktivitas masyarakat dalam pengelolaan dusung mulai dari persiapan, penanaman hingga pasca panen. 
Proses penelitian meliputi : 1 . Tahap persiapan yakni perumusan masalah dan tujuan penelitian, permasalahan yang terkait dengan topik penelitian, kajian pustaka dan teori, penentuan metode dan penyusunan kuisioner. 2). Tahap pelaksanaan meliputi : pengambilan data primer melalui wawancara dan observasi

HASIL DAN PEMBAHASAN

\section{Tahapan Pengelolaan Dusung}

Kondisi awal dusung sebelum dikelola berupa ewang (hutan alam primer) yang penuh dengan semak belukar, liana dan pohon-pohon yang besar. Kegiatan

Tahap 1.Persiapan : Pada tahap ini pohon ditebang/ditebas dan dilakukan pembersihan semak-belukar dan liana dengan menggunakan parang sedangkan beberapa pohon besar dibiarkan tumbuh sebagai pelindung. selanjutnya pohon, liana dan semak belukar yang telah kering

Tahap 2.Penanaman : Tahap penanaman biasanya dilakukan pada awal musim hujan. Pola tanam didusung umumnya merupakan pola tanam ganda yakni pada satu areal ditanam berbagai jenis tanaman yang merupakan kombinasi tanaman setahun/umur pendek (annual crops), tanaman tahunan (perennial crops) dan tanaman kehutanan (forest crops). langsung di lapangan, pengambilan data sekunder dari instansi terkait. 3). Evaluasi dan penyempurnaan data , 4) analisis data hasil penelitian 5). Penulisan hasil penelitian meliputi interprestasi data, verifikasi, pengakjian hasil dan kesimpulan.

masyarakat di desa Soya dalam mengelolah dusung biasanya diawali dengan mencari dan menentukan lokasi untuk dibuka lahan dan biasanya disesuaikan dengan jenis yang akan ditanam. Adapun tahapan pengelolaan dusung adalah sebagai berikut :

kemudian dikumpulkan dan dibakar dengan tujuan untuk memudahkan proses penanam. Jika masih ada ssa-sisa ranting pohon dan semak belukar yang tidak terbakar dikumpulkan kemudian dibakar kembali dan tanahnya digemburkan untuk siap ditanam

Tanaman hanya ditanam pada sela-sela tanaman lain atau diantara batu-batu tanpa jarak tanam tertentu . Dusung yang letaknya jauh dati pemukiman/tempat tinggal biasanya ditanami dengan tanaman umur panjang seperti cengkih (Eugena aromaticum) dan pala (Meristica fragrans), dan durian (Durio zibethinus) kayu besi (Instia bijuga) kenari 
(Paraserianthes falcataria). Sedangkan dusung yang letaknya dekat dengan pemukiman atau tempat tinggal ditanami dengan tanaman umur pendek seperti pertanian yang dominan ditanam yakni umbi-umbian : kacang tanah, jagung,

Tahap 3.Pemeliharaan : Tahapan pemeliharaan dilakukan setelah penanaman yakni pembersihan (penyiangan) tanaman bawah dengan cara Tahap 4.Pemanenan: setiap tanaman memiliki umur panen yang berbeda. Proses pemanenan dilakukan pada saat tanaman mencapai umur masak panen yang ditandai dengan sifat fisik tanaman yakni warna dan bau. Saat musim panen tiba, masyarakat membuat rumah kebun (walang)untuk mengumpulkan dan

Tahap 5.Pemasaran: Biasanya kegiatan pemasaran lebih banyak didominasi oleh kaum ibu. Rantai pemasaran hasil dusung terbagi menjadi 2 yaitu :

1. Rantai pemasaran dengan pelaku terdiri dari : pemilik dusung dan konsumen

Tahap 6. Pengolahan pasca panen: Setelah pemanenan, selanjutnya masyarakat dengan cara yang masih sangat sederhana hasil dusung tersebut diolah. Sedangkan lahan bekas tanaman di dusung telah dipanen biasanya dibiarkan begitu saja (aong) setelah 2-3 tahun baru ditanami lagi dari awal seperti daur yang telah singkong (Manihot pescaprea), Pisang (Musa paradisiacal) agar muda untuk diambil untuk memenuhi kebutuhan sehari-hari.

Tanaman keladi, patatas yang oleh masyarakat dinamakan isi kabong.

mencabut rumput, liana dan semak belukar yang tumbuh diantara tanaman pokok dengan tujuan untuk memberi ruang tumbuh bagi tanaman.

menjaga hasil panen. Sudah menjadi suatu kebiasaan dari masyarakat Hulaliu jika musim panen buah durian tiba maka hasilnya akan diambil secara bergiliran oleh setiap keluarga yang termasuk dalam ikatan keluarga yang memiliki dusung dati(dusung yang dimiliki secara kolektif oleh mata rumah (clan).

2. Rantai pemasaran dengan pelaku terdiri dari : pemilik dusung, orang papalele (pedagang pengumpul) dan konsumen.

dilakukan. Ini dimaksud agar lahan tersebut secara alami dapat produktif lagi. Untuk pengolahan hasil panen masyarakat lebih mengutamakan untuk memenuhi kebutuhan sehari-hari dan jika ada kelebihan barulah dijual. Pengelolaan hasil panen pun masih dilakukan dengan sederhana misalnya durian dibuat dodol, 
dan singkong diolah menjadi keripik Manajemen Pengelolaan dan Pengembangan Dusung

Fungsi manajemen sangat penting karena seluruh kegiatan diperlukan perencanaan, pengorganisasian, pengarahan dan pengendalian secara optimal.Hal ini dapat dilakukan bila manajemen dalam keadaan siap guna menunjang seluruh fungsi yang ada. Out put yang diberikan adalah program dan

\section{Perencanaan (Planning)}

Perencanaan (planning)merupakan penyusunan pola tentang peruntukan, penyediaan, pengadaan dan penggunaan hutan secara serbaguna dan lestari serta penyusunan pola kegiatan-kegiatan pelaksanaannya menurut ruang dan waktu.Perencanaan merupakan tahapan penting dalam mewujudkan tujuan pengelolaan hutan.Dari segi perencanaan

\section{Pengorganisasian (organization)}

Pengorganisasian (organization) merupakan proses penentuan struktur dan alokasi kerja dengan koordinasi dan usaha melalui penataan pola struktur, tugas, otoritas tenaga kerja dan komunikasi. Kelompok tani adalah kumpulan petani dalan suatu wadah organisasi yang tumbuh berdasarkan kebersamaan, keserasian, kesamaan profesi dan kepentingan dalam dengan aneka rasa.

tindakan implementasinya di lapangan. Kesiapan manajemen dalam pengelolaan hutan ini dipengaruhi oleh kesiapan faktorfaktornya baik internal maupun eksternal yang dapat mendukung efektifitas dan efisien suatu kegiatan. Adapun manajemen pengelolaan dusung Hulaliu memiliki karakter dan ciri tersendiri. Berdasarkan kajian yang dilakukan maka manajemen pengelolaan dan pengembangan dusung di desa Hulaliu meliputi :

kegiatan pengelolaan dan pengembangan dusung di desa Hulaliu masih dilakukan baik oleh individu maupun kelompok masih dilakukan secara sendiri-sendiri dan atau jika ada program pemerintah. Misalnya untuk jenis apa yang akan ditanam di dusung, kapan akan dilakukan dan siapa yang akan mengelolah ditentukan masing-masing oleh pemilik dusung.

memanfaatkan sumber daya alam yang mereka kuasai dan berkepentingan untuk bekerjasama dalam rangka meningkatkan produktifitas produksi usaha tani dan kesejahteraan anggotanya. Ataupun bukan merupakan organisasi formal tetapi dalam pengelolaan dusung ini ada kelompokkelompok masohi yang saling membantu mulai dari penanaman hingga pemanenan. 
Pelaksanaan (actualization) yaitu proses bimbingan pelaksanaan aktual pada bawahannya menuju kesasaran bersama. Dalam pengelolaan dusung terdapat pembagian tugas bahwa yang mana pohon dan mencangkul sedangkan kaum perempuan membersihkan liana sedangkan untuk menanam biasa dikerjakan oleh kaum laki-laki maupun perempuan.

- Dalam pengelolaan dusung masyarakat/kelompok masohi biasanya

\section{Pengawasan(Controling)}

Pengawasan terhadap jalannya pekerjaan merupakan salah satu tahapan yang menentukan keberhasilan kegiatan ini. Dalam pengelolaan dusung ada berbagai kearifan lokal yang diterapkan agar tradisi dan budaya tersebut secara terus menerus diwarisi oleh generasi muda. Bentuk kearifan lokal yang berlaku terkait dengan pengelolaan dusung yakni sasi (larangan) merupakan larangan untuk mengambil/memungut/melakukan pemanenan hasil dusung sebelum waktu. Pemberlakuan dan pelaksaan sasi bertujuan untuk menjaga kualitas dan

Pengeloaan dan pengembangan dusung pun tidak lepas dari tugas dan tanggungjawab dari lembaga adat Kewang (lembaga desa yang diangkat untuk menjaga pemanfaatn sumber daya alam tugasnya seperti polisi hutan). pekerjaan yang mesti dikerjakan oleh kaum perempuan dan mana pekerjaan yang dilakukan oleh kaum laki-laki. Misalnya : kaum laki-laki bekerja menebang

saling membantu secara masohi (gotongroyong) mulai dari persiapan hingga pemanenan hasil dusung dan dilakukan secara bergiliran ataupun secara berbalasan.

kuantitas sumber daya alam misalnya hasil dusung akan tetap lestari dan berkelanjutan. Sasi yang berlaku di desa Hulaliu yakni sasi adat (sasi negri) dan sasi gereja. Dusung yang sasi diberi tanda khusus agar jika ada yang lihat tanda tersebut akan mengetahui bahwa dusung tersebut sementara disasi jadi hasilnya tidak boleh diambil. Jika ada yang mengambil maka akan dikenakan sanksi/denda sesuai ketentuan berdasarkan besarnya kesalahan yang dibuat dan tidak diperbolehkan lagi untuk mengambil hasil di area sasi dalam jangka tertentu.

Kewang inilah yang melakukan pengawasan terhadap pemanfaatan sumber daya alam maupun menjaga batas-batas petuanan desa Hulaliu. Masa tugas kewang sesuai dengan masa jabatan Raja (kepala desa) dan akan dilakukan 
pemilihan lagi seiring pergantian jabatan seorang raja. Namun terkait dengan masa transisi pemerintahaan yang terjadi di desa Hulaliu yang di pegang oleh PJS (

\subsection{Masohi sebagai suatu bentuk}

\section{kearifan lokal}

Masyarakat desa Hulaliu dalam pegelolaan agroforestry dusung masih dilakukan oleh sebagian besar petani

1). Masohi Bilang : sistem
masohi dimana secara
perorangan mengajak orang lain
untuk membantu melakukan
suatu pekerjaan dan pekerjaan
yang dilakukan tersebut
merupakan awali pada dusung
orang pertama dalam system
masohi.

2) Masohi Balas : orang kedua membalas pekerjaan bagi orang pertama dengan pekerjaan yang Kerja masohi "gotong-royong" ini biasanya dilakukan oleh beberapa orang dalam dua atau lebih kelompok secara bergantian atau berbalas-balasan hingga suatu pekerjaan itu selesai. Mengingat di era globalisasi yang semuanya serta instan dengan gaya hidup yang meterialistis setidaknya lama kelamaan akan memudarkan tradisi gotong-royong yang ada di masyarakat. Seperti halnya untuk sebagain kalangan masyarakat masohi gotong-royong ini telah diganti dengan penjabat sementara) maka dengan berbagai kebijakan di desa maupun proses pembangunan masih ditanggukan hingga ada pemerintah yang depenitif.

karena hal ini dirasakan sangat membantu serta meringankan beban kerja serta biaya yang dikeluarkan. Dalam pengelolaan dusung biasanya kerja masohi terdiri dari beberapa pola yakni :

sama misal : masohi tanam dibalas dengan masohi tanam

3) Masohi Kumpul : beberapa orang secara bersama dan bergiliran melakukan suatu pekerjaan biasanya dilakukan lebih dari 10 orang hingga setiap orang mendapat giliran atau berpindah dari orang ke-10 hingga orang ke 10 hingga pekerjaan tersebut selesai.

pola kerja "sewa" atau borong karena menurut mereka tidak usah berlelah-lelah untuk gotong-royong jika ada uang untuk membayar orang untuk pengelolah dusung seperti : mencangkul dalam proses membuka lahan dilakukan dengan pola kerja sewa ataupun memanen dengan cara membagi hasil. Hal ini akan berdampak bagi tradisi pengelolaan dusung berbasis masohi dan pudarnya dan nilai-nilai sosial dan kegotong-royongan dalam masyarakat. Dengan memikian pola pengelolaan 
dusung berbsis masohi mesti tetap terus dipertahankan sehingga dapat menjadi

Kelompok Masohi Ina-Ama desa Hulaliu keberadaannya dirasakan sangat membantu berbagai pekerjaan dalam pengelolaan dan pengembangan dusung dan mempertahankann budaya dan tradisi lokal. Namun karena berbagai perkembangan yang terjadi di masyarakat menyebabkan fungsi dan peran kelompok ini hanya jika dibutuhkan saja. Berdasarkan uraian di atas jika ditelaah Berdasarkan hasil kajian untuk pengembangan yang dilakukan dalam pengelolaan agroforestry tradisional dusung di negeri Hulaliu antara lain :

1. Sosialsasi dan Penyuluhan : kegiatan sosialisasi dan penyuluhan oleh tim staf pengajar Universitas Pattimura dimaksudkan untuk menambah pengetahuan masyrakat, materi yang disampaikan

2. Pengadaan peralatan utama dan peralatan penunjang panen/ produksi dan pemasaran dimaksudkan untuk menunjang kegiatan produksi dan pemasaran. Peralatan utama antara lain : mesin parut singkong, mesin potong rumput dan peralatan produksi tepung singgong basah (toya). Pengemasan produk tepung singgong basah toya) untuk dijual karena selama pengemasan masih dilakulan secara sederhana pada wadah-wadah bekas. Distribusi produk ke konsumen dengan menjualnya modal sosial bagi kehidupan masyarakat kini dan nanti.

lebih jauh tentang pengelolaan dusung berbasis masohi maka semestinya ada nilai yang harus tetap dipertahankan dari generasi ke generasi secara terus menerus dan berkelanjutan karena jika tidak maka akan terjadi kesingpangsiuran dalam pengelolaan sumber daya alam maupun terpuruknya nilai-nilai sosial dan kegotong-royongan dalam masyakarat.

untuk kalangan masyarakat yang ada di desa Hulaliu ataupun yang ada di kota Ambon dan sekitarnya.

3. Pengkayaan jenis tanaman di dusung yakni dengan melakukan penanaman 100 anakan rambutan dan 100 anakan kayu besi serta 1500 stek singkong pada 2 areal dengan jarak tanam tertentu karena selama ini praktek pengelolaan dusung yang dilakukan oleh masyarakat yakni melakukan penanaman tanpa jarak tanam atau sebagai tanaman selsaja. Dengan demikian dusung terlihat lebih tertata dan terawat.

4. Pendampingan dan Kerja sama dengan instansi terkait yakni Balai Perhutanan Sosial dan Kemitraan Lingkungan wilayah Maluku dan Papua dalam melalui Kegiatan Pengembangan Perhutanan Sosial Nusantara dengan 
memberikan bantuan biaya

\section{KESIMPULAN}

1. Pengelolaan dusung oleh masyarakat di desa Hulaliu diawali dengan menentukan lokasi, persiapan (penebangan/penebasan), pembersihan sisa tebangan dan pembakaran, penanaman, pemeliharaan (penyiangan, pembersihan gulma), pemanenan, pemasaran dan pengelolaan pasca panen.

2. Manajemen pengelolaan dan pengembangan agroforestry tradisional dusung di desa Hulaliu terdiri dari perencanaan (planning)

\section{DAFTAR PUSTAKA}

Ajawailla, J.W. 1996. Potensi Sosial Budaya Agroforestry Dusung. Pusat Studi Maluku, Universitas Pattimura Ambon

Ambar T, 2004.Kemitraan dan Modelmodel Pemberdayaan, Penerbit Gava Media

Franz, J.J.1993. Pola Dusung Salah Satu Alternatif Pengelolaan Sumber Daya Hutan di Maluku. Makalah disampaikan pada Seminar Pertanian Kepulauan. Fakultas Pertanian Universitas Pattimura Ambon

Kaya, M.2003. Dusung, Sistem Pengelolaan Lahan Tradisional. Dinas Kehutanan Provinsi Maluku pengorganisasian (organization), pelaksanaan (actualization) dan pengawasan (Controlling.

3. Jenis-jenis kerja masohi dalam pengeloaan dusung diantaranya : 1) Masohi bilang 2) Masohi balas 3) Masohi kumpul.

4. Upaya pengembangan yang dilakukan dalam pengelolaan agroforestry tradisional dusng yakni penyuluhan dan sosialisasi, pengadaan peralatan produksi dan pemasana, pengkayaan jenis tanaman, dan pendampingan kelompoik tani.

Sahureka M, 2015. Konsep Manajemen Pengelolaan Agroforestry Tradisonal dusung (Kajian di Desa soya) Prosiding seminar nasional agroforsetry ke 5

Silaya Th.2016, Kerafifan Masyarakat Lokal dalam pengelolaan sumberdaya hutan di wilayah pegunungan Manusela, Seram Utara.,Jurnal Makila Vol IX nomor 1. Jurusan Kehutanan Universitas Pattimura Ambon.

Suparjan dan Hempri Suyatno, 2003.

Pengembangan Masyarakat dari Pembangunan sampai Pemberdayaan. Penerbit Aditya Media Yogyakarta 
Supranto J. 1990, Teknik Riset Pemasaran

Rineka Cipta Jakarta dan Ramalan Penjualan.Penerbit 